\title{
ANÁLISE DA ABORDAGEM E CONHECIMENTO DO TEMA PARASITOSES CAUSADAS POR PROTOZOÁRIOS EM ESCOLAS PÚBLICAS DO MUNICÍPIO DE SALINAS-MG
}

\author{
Larissa Mendes SANTOS \& Nathália Bastos LIMA*
}

Instituto Federal do Norte de Minas Gerais - Campus Salinas. Salinas, Minas Gerais, Brasil

*Autor para correspondência: nathalia.andrade@ifnmg.edu.br

DOI: http://dx.doi.org/10.18571/acbm.146

\section{RESUMO}

As parasitoses são doenças que trazem prejuízos à população e estão presentes em muitas regiões, sendo as ocasionadas por protozoários bem comuns no Norte de Minas Gerais. Este trabalho visa analisar o grau de conhecimento sobre o tema "Parasitoses humanas causadas por protozoários", nas turmas de terceiro ano do Ensino Médio em escolas públicas do município de Salinas-MG. Para isso foram aplicados questionários sobre as doenças causadas por protozoários, os sintomas, fases clínicas da doença, exemplos de protozoários e mecanismos de transmissão. Além disso, foi aplicado um questionário para os docentes que ministram a disciplina de Biologia para verificar a visão quanto ao ensino do conteúdo Parasitologia e como este é abordado em sala de aula, e por fim analisou-se o livro utilizado pelos docentes, caracterizando o conteúdo das parasitoses causadas por protozoários quanto à linguagem utilizada e atividades propostas. Os resultados indicam que os estudantes precisam adquirir um melhor aprendizado significativo sobre o tema, mostrando a necessidade de se enfatizar alguns pontos. Também foi observado que os docentes se mostraram preocupados em abordar esse conteúdo apesar de não terem recursos suficientes para isso. O livro didático analisado aborda este conteúdo de forma superficial e não enfatiza pontos importantes como medidas de prevenção e formas de contágio. Com isso foi possível concluir que a educação para saúde deveria ser trabalhada de forma transversal para que os alunos sejam autores de suas próprias mudanças.

Palavras-chave: Parasitologia; Educação; Saúde; Doenças; Ensino Médio.

\begin{abstract}
Human parasitoses are diseases harmful for population and are found mainly in poor regions. They are caused by protozoan organisms and show high levels at the north of Minas Gerais state. This work aims to analize the knowledge of highscool students from public schools of Salinas (MG) city about the theme "Human parasitosis caused by protozoa". To do that, questionnaires were applied including symptoms, clinical phases of the different diseases, examples of protozoa and transmission mechanisms. Beyond that, teaches which give classes about the subject were also argued to verify their vision about the teaching-learning process about parasitology and how it is approached at the classroom. Finally the textbook used was analyzed aiming to characterize its content about the protozoa parasitic diseases, as well the language used and exercises proposal. The results showed that the students have to acquire a meaningful learning about the theme, highlighting the need of some adjustments for a better learning. The teachers were concerned to make an adequate approach of the content at the classroom, despite of they not have enough resources to work the content, once they receive a basic pedagogic material. The textbook analyzed approaches the content superficially and do not emphasize important points, as preventive actions and transmission forms. With this work, it was possible to conclude that health education should be worked as transversally as possible, allowing the students understand these information and making them authors of their change.
\end{abstract}

Keywords: Parasitology; Education; Health; Diseases; Highschool. 


\section{Introdução}

A parasitologia é um ramo das Ciências que estuda a morfologia, fisiologia e ciclo de vida de organismos que infectam outros seres vivos. Engloba o filo Protozoa, do Reino Protista e os filos Nematoda, Platyhelminthes e Arthropoda, pertencentes ao Reino Animalia. Esses seres vivos estabelecem uma relação com os seus hospedeiros, se beneficiando destes e prejudicando-os em prol de sua sobrevivência (NEVES, 2005). Dentre esses filos, os protozoários são responsáveis por causarem as "protozoozes", doenças muito comuns na população como Leishmaniose, Doença de Chagas, Amebíase e Malária.

As doenças causadas por parasitas trazem prejuízos para a população, pois são doenças relacionadas com fatores sociais como pobreza e qualidade de vida (PAES e SILVA, 1999). Nesse sentido, doenças parasitárias afetam imensamente a qualidade de vida das pessoas, podendo também contribuir para o aumento do índice de mortalidade. Essas patogenias incluem frequentemente sintomas como diarreia crônica, desnutrição e prejuízo na função de órgãos vitais, além de comprometer o desenvolvimento físico e/ou intelectual de pessoas mais jovens (SILVA e SANTOS, 2001). Segundo a OMS (Organização Mundial de Saúde), as doenças parasitárias atingem milhares de pessoas. Estima-se que, a cada quatro pessoas, uma encontra-se infectada (WORLD HEALTH ORGANIZATION, 2013).

A falta de informação da população sobre a transmissão e as medidas profiláticas é um dos principais fatores que contribuem para a propagação dessas doenças, uma vez que, o investimento do governo com a saúde pública ainda é insuficiente e requer mais verbas a fim de melhorar as condições de vida das pessoas mais carentes. Dessa forma a educação se torna um dos caminhos mais importantes e deve ser entendida como uma vertente associada a prevenção, e que na prática contribua para melhorar as condições de vida das pessoas (OLIVEIRA e GONÇALVES, 2004).

O presente trabalho pretende compreender como a Parasitologia é abordada no Ensino Médio na cidade de Salinas (MG), visto que parasitoses causadas por protozoários são bastante comuns na nossa região. Dessa forma, pretendemos averiguar se a temática "Educação para Saúde" é trabalhada como preconiza a proposta dos PCNs, pois, entende-se que educar para saúde frisando as parasitoses é de suma importância e a escola torna-se um dos ambientes mais favoráveis para promover este tipo de conhecimento, pois o que os estudantes vêem na escola pode fazer parte do seu dia a dia. Focamos em avaliar os conhecimentos dos alunos sobre parasitoses causadas por protozoários através da aplicação de questionários, e descrever as estratégias e materiais pedagógicos utilizados no processo de ensino-aprendizagem no contexto do tema parasitologia nas turmas de $3^{\circ}$ ano do Ensino Médio das duas modalidades de Ensino (Estadual e Federal). Também foi avaliado o livro didático utilizado pelos docentes da rede Estadual e Federal quanto ao aprofundamento do conteúdo e se os conceitos estavam devidamente abordados.

\section{Material e Métodos}

\section{1 Área de estudo e público alvo}

A presente pesquisa é uma abordagem quali-quantitativa, onde os dados foram coletados com o auxílio de um questionário contendo dez questões, aplicados para os discentes do ensino médio, de algumas escolas da Rede Federal e Estadual do município de Salinas (MG). Também foi aplicado um questionário para os docentes que ministram a disciplina de Biologia e o material pedagógico utilizado por estes foi analisado quanto à abordagem do tema Parasitologia. O público alvo engloba cerca de 300 alunos e três professores do terceiro ano do Ensino Médio, de escolas públicas da cidade de Salinas (MG). Para guardar o anonimato das Escolas, estas foram identificadas como Escola 1, Escola 2 e Escola 3. As escolas foram selecionadas de acordo com a disponibilidade da direção e dos docentes para a realização deste estudo. 


\section{Biomedica Brasiliensia}

\subsection{Análise do livro didático}

No presente estudo foi feita a análise do livro didático BIOLOGIA HOJE (LINHARES e GEWANDSZNAJDER, 2014) utilizado pelos docentes de todas as escolas, caracterizando o conteúdo das parasitoses causadas por protozoários (quanto aos ciclos de vida, profilaxia, tratamento, sintomas e transmissão), a linguagem utilizada e atividades propostas através de um roteiro utilizado por Moreira (2014). A partir da análise desse conteúdo, foi elaborado o questionário dos discentes.

\subsection{Análise dos questionários}

Os questionários dos discentes foram analisados verificando-se a porcentagem de erros e acertos para cada, das três escolas. Os questionários dos docentes foram analisados para verificar visão dos professores quanto ao ensino do conteúdo Parasitologia e como este é abordado em sala de aula. Os docentes e discentes que participaram da pesquisa foram estavam cientes que seu nome e imagem não seriam expostos em nenhum momento da pesquisa, através da assinatura do Termo de consentimento Livre e Esclarecido, presente em cada questionário.

\section{Resultados e Discussão}

\subsection{Análise do questionário aplicado para os discentes}

A pesquisa realizada com os discentes pretendia analisar o conhecimento dos estudantes sobre as parasitoses humanas causadas por protozoários, aplicado por meio de um questionário para 300 alunos.

Na questão 1, quando solicitados a fazer uma correlação entre os organismos citados no questionário e a que Filo eles pertenciam, foi observado que a maioria dos estudantes da escola 1 respondeu corretamente que a ameba pertence ao filo dos protozoários, a lombriga pertence aos nematódeos, tênia aos platelmintos e o carrapato aos artrópodes (Tabela 1). Já nas escolas 2 e 3, pouco menos da metade dos estudantes respondeu corretamente a questão, o que demonstra que muitos estudantes possuem dificuldades em discernir sobre as filogenias dos organismos.

Tabela 1: Respostas dos discentes para a pergunta 1 do questionário: A parasitologia é uma ciência que estuda a morfologia, fisiologia e ciclo de vida de parasitas que infectam outros seres vivos. Como exemplos temos: Ameba, Lombriga, Tênia e Carrapato. Os organismos citados fazem parte de quais filos, respectivamente?

\begin{tabular}{lccc}
\multicolumn{1}{c}{ Resposta dos estudantes } & Escola 1 & Escola 2 & Escola 3 \\
\hline $\begin{array}{l}\text { Protozoários, Nematódeos, Platelmintos } \\
\text { e Artrópodes }\end{array}$ & $78,4 \%$ & $45 \%$ & $45,3 \%$ \\
$\begin{array}{l}\text { Platelmintos, Cnidários, Poríferos e } \\
\text { Nematódeos } \\
\text { Mamíferos, Artrópodes, Anelídeos e Helmintos }\end{array}$ & $8,8 \%$ & $13,5 \%$ & $29,7 \%$ \\
Protozoários, Bactérias, Equinodermos e Fungos & $0,8 \%$ & $6,3 \%$ & $1,6 \%$ \\
Sem resposta & $12 \%$ & $33,3 \%$ & $23,4 \%$ \\
\hline
\end{tabular}

Quando questionados sobre exemplos de parasitas que pertencem ao filo dos protozoários (pergunta 2 do questionário), a maioria dos estudantes das três escolas disseram corretamente que a Ameba pertence a esse filo. Menos de $20 \%$ dos estudantes marcaram corretamente que tripanossoma, giárdia e toxoplasma são protozoários. Isso indica que os estudantes ainda confundem conceitos, uma vez que encontram muitas dificuldades em taxonomia. Corroborando, muitos estudantes das Escolas 2 e 3 (20,9\% e 25,3\%) disseram que a Tênia é exemplo de protozoário, dessa forma esse aspecto precisa ter mais enfoque em sala de aula (Figura 1). 


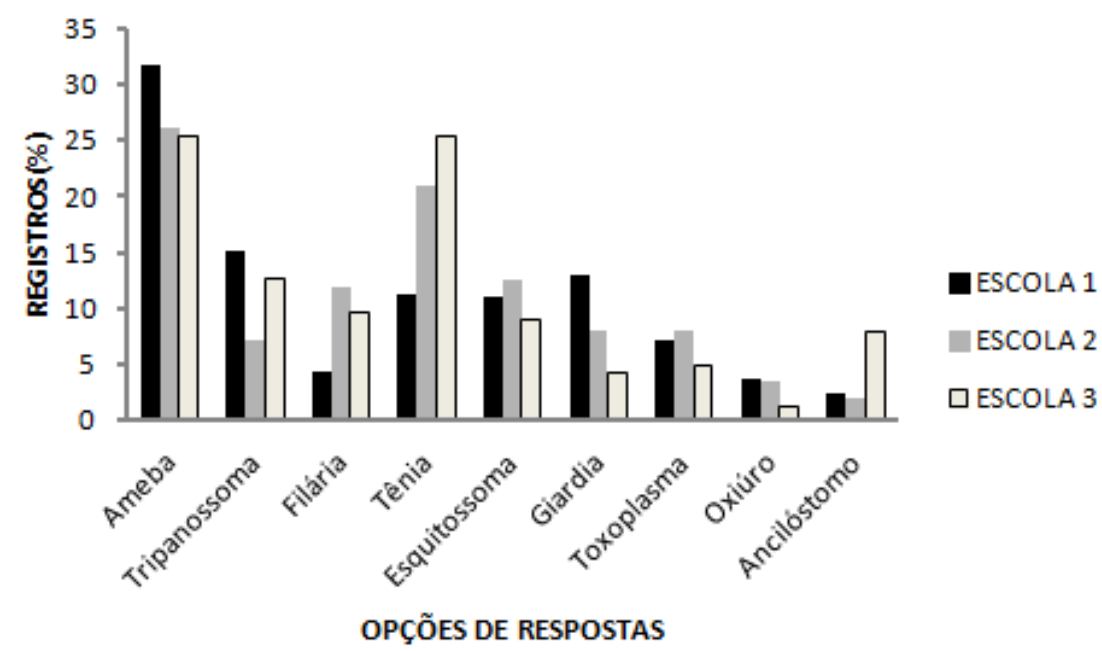

Figura 1: Respostas dos estudantes para a questão 2: “Os protozoários são organismos muito importantes para a natureza, porém algumas espécies são parasitas dos seres humanos e causadores de diversas doenças. Alguns exemplos de organismos do Filo Protozoa (protozoários) são.

Quando questionados sobre as doenças causadas por protozoários que conhecem, a maioria dos alunos disseram conhecer a Doença de Chagas (99,6 \%), Malária (67,9 \%), Leishmaniose $(62,4 \%)$ e Amebíase (33,5\%), que, segundo Moreira (2014), são doenças que mais atingem o ser humano (Figura 2), dessa forma os professores podem preconizá-las em suas aulas visando a conscientização de seus estudantes.

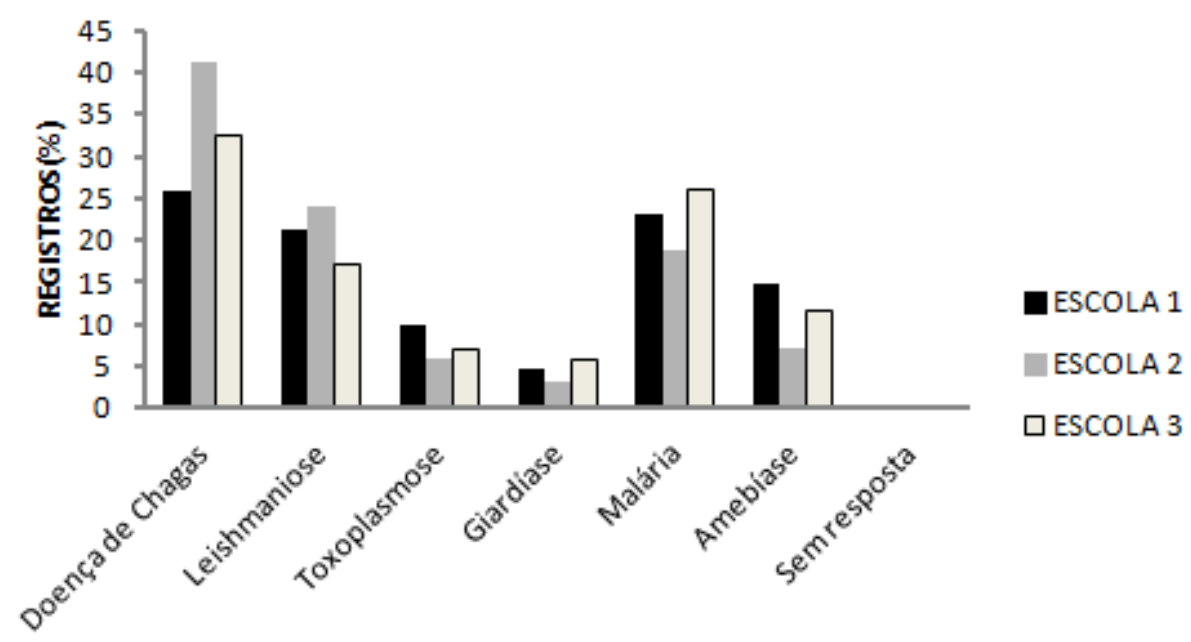

\section{OPÇÕES DE RESPOSTA}

Figura 2: Respostas dos alunos para a questão 3. "Marque as doenças abaixo as quais você conhece".

Sobre como ocorre a transmissão da Doença de Chagas ao ser humano, a maioria dos discentes disseram corretamente que é "Através da picada do barbeiro, onde o protozoário sai pelas fezes do inseto e penetra o orifício deixado pela picada, infectando a pessoa quando ela se coça". Essa resposta foi dada por $63 \%$ dos estudantes na escola 1, 52,2\% na escola 2 e 68,8\% na escola 3 (Tabela 2). Sendo assim, grande parte dos alunos são informados sobre a transmissão da Doença de Chagas, visto que são bastante comuns na região, pois segundo Silva et al., (2010), um dos estados brasileiros considerado com maior prevalência de Doença de Chagas é o estado de Minas Gerais . Uma porcentagem elevada de estudantes respondeu este questionamento de forma incorreta, o que mostra a necessidade de enfatizar a importância de se conhecer sobre esta doença e seus mecanismos de prevenção. 
Tabela 2: Respostas dos discentes para a pergunta 4 do questionário. "A doença de Chagas é causada pelo protozoário Trypanosoma cruzi, transmitido pelo "barbeiro". Como esse animal infecta uma pessoa?"

\begin{tabular}{lccc}
\hline Respostas dos estudantes & Escola 1 & Escola 2 & Escola 3 \\
\hline $\begin{array}{l}\text { Através da picada do mosquito, o protozoário entra pelo } \\
\text { local onde houve a picada e se multiplica }\end{array}$ & $19,2 \%$ & $27 \%$ & $20,3 \%$ \\
$\begin{array}{l}\text { Através da picada do barbeiro, o protozoário sai pelas } \\
\text { fezes do inseto e penetra o orifício deixado pela picada, } \\
\text { infectando a pessoa quando ela se coça. }\end{array}$ & $63,2 \%$ & $52,2 \%$ & $68,8 \%$ \\
$\begin{array}{l}\text { O protozoário aloja-se na pele da pessoa e se reproduz, } \\
\text { se espalhando pelo organismo. }\end{array}$ & $12 \%$ & $10 \%$ & $6,2 \%$ \\
$\begin{array}{l}\text { Através dos alimentos contaminados por ovos do } \\
\text { barbeiro. }\end{array}$ & $5,6 \%$ & $10,8 \%$ & $4,7 \%$
\end{tabular}

Quando questionados sobre as fases clinicas que compõem a doença de Chagas (Tabela 3), 63,2\% dos alunos da escola 1 e 45,3\% dos discentes da escola 3 responderam corretamente que essa doença é caracterizada por uma fase aguda, onde há multiplicação e invasão das células, ocasionando inflamação em vários órgãos e uma fase crônica, onde os protozoários que sobreviveram irão causar os sintomas característicos da doença (dilatação do coração, esôfago e cólon). Porém, as escolas 2 e 3 apresentaram mais de $40 \%$ de respostas para a opção C ("Fase 1, mais leve, onde o indivíduo não percebe os sintomas da doença, e o parasita se desenvolve podendo evoluir para fase 2, mais agressiva quando o parasita infecta todos os órgãos da pessoa"). Deste modo, esse ponto deve ser mais trabalhado nessa escola, de forma que os alunos saibam discernir corretamente as fases dessa doença.

Tabela 3: Respostas dos discentes para a pergunta 5 do questionário: "A doença de Chagas possui duas fases clinicas. Estas são".

\begin{tabular}{lccc}
\hline Respostas dos estudantes & Escola 1 & Escola 2 & Escola 3 \\
\hline $\begin{array}{l}\text { Fase A, onde o protozoário se multiplica no intestino e ocasiona } \\
\text { o aumento do coração, pulmão e bexiga e fase B, quando o } \\
\text { protozoário é totalmente eliminado pelo organismo, através do } \\
\text { sistema imunológico }\end{array}$ & $7,2 \%$ & $11,8 \%$ & $12,6 \%$ \\
$\begin{array}{l}\text { Fase aguda, onde há multiplicação e invasão das células, } \\
\text { ocasionando inflamação em vários órgãos. Fase crônica, onde os } \\
\text { protozoários que sobreviveram irão causar os sintomas } \\
\text { característicos da doença (dilatação do coração, esôfago e cólon) }\end{array}$ & $63,2 \%$ & $39,6 \%$ & $45,3 \%$ \\
$\begin{array}{l}\text { Fase 1, mais leve, onde o indivíduo não percebe os sintomas da } \\
\text { doença, e o parasita se desenvolve podendo evoluir para fase 2, } \\
\text { mais agressiva quando o parasita infecta todos os órgãos da } \\
\text { pessoa. }\end{array}$ & $29,6 \%$ & $48,6 \%$ & $42,1 \%$ \\
\hline
\end{tabular}

Quando solicitados para marcar as formas de transmissão da Leishmaniose, 48,8 \% dos alunos da escola 1 e 43,2\% dos alunos da escola 2 respectivamente, responderam corretamente que ocorre devido por picadas de uma espécie de mosquito (Tabela 4). Já a maioria dos alunos da escola $3(36 \%)$, consideram que a transmissão dessa doença ocorre por consumo de carne mal passada. O mesmo pode ser observado para os sintomas da Leishmaniose, onde poucos estudantes consideraram corretamente que são lesões que não curam na pele podendo afetar nariz, boca e faringe; febre e anemia (Tabela 5).

Isso confirma o desconhecimento da doença pela maioria dos estudantes, mostrando que, apesar de ser uma doença grave muito comum no norte de Minas Gerais, ela ainda deve ter mais ênfase em sala de aula, pois ainda há o desconhecimento sobre informações básicas sobre a doença. Portanto aprofundar esse tema é de suma importância. 
Tabela 4: Respostas dos discentes para a pergunta 6 do questionário: “A Leishmaniose é uma doença causada por protozoários do gênero Leishmania. Essa patogenia pode ser transmitida:"

\begin{tabular}{lccc}
\hline Respostas dos estudantes & Escola 1 & Escola 2 & Escola 3 \\
\hline Através de verduras mal lavadas & $7,2 \%$ & $9 \%$ & $36 \%$ \\
Por picadas de uma espécie de mosquito & $48,8 \%$ & $43,2 \%$ & $18,7 \%$ \\
Através da água contaminada & $30,4 \%$ & $25,2 \%$ & $18,7 \%$ \\
Por meio do consumo de carne malpassada & $13,6 \%$ & $22,6 \%$ & $25 \%$ \\
Sem resposta & - & - & $1,6 \%$ \\
\hline
\end{tabular}

Tabela 5: Respostas dos discentes para a pergunta 7 do questionário: "Existem diferentes sintomas que caracterizam a doença Leshmaniose, que podem se manifestar dependendo do organismo afetado. Os principais são".

\begin{tabular}{|c|c|c|c|}
\hline Respostas das estudantes & Escola 1 & Escola 2 & Escola 3 \\
\hline $\begin{array}{l}\text { Lesões que não curam na pele podendo afetar nariz, boca e } \\
\text { faringe; febre e anemia }\end{array}$ & $37,6 \%$ & $37 \%$ & $6,2 \%$ \\
\hline Diarreia, febre e desnutrição; alergia, gripe e inchaço & $35,2 \%$ & $29,7 \%$ & $56,2 \%$ \\
\hline Gripe, diarreia e cólicas; anemia e coceiras & $5,6 \%$ & $8,1 \%$ & $12,6 \%$ \\
\hline Coceira, infecção; dores abdominais e febre & $21,6 \%$ & $25,2 \%$ & $25 \%$ \\
\hline
\end{tabular}

Quando questionados sobre o que ocorre com o organismo após ser contaminado pelo protozoário que causa a malária, a maioria dos alunos das três escolas respondeu corretamente que o protozoário invade as hemácias e causa ruptura destas, ocasionando hemorragias (Tabela 6). Dessa forma é possível notar que os alunos compreenderam corretamente sobre os mecanismos dessa doença.

Tabela 6: Respostas dos discentes para a pergunta 8 do questionário: “A Malária é uma doença muito comum em países tropicais, e no Brasil a maioria dos casos ocorre na região amazônica. Essa patogenia é causada por um protozoário chamado plasmódio, transmitido através da picada de mosquito. O que acontece com o organismo após ser contaminado?".

\begin{tabular}{lccc}
\hline Respostas dos estudantes & Escola 1 & Escola 2 & Escola 3 \\
\hline $\begin{array}{l}\text { O protozoário invade as hemácias e causam } \\
\text { ruptura destas, ocasionando hemorragias }\end{array}$ & $66,4 \%$ & $50,4 \%$ & $65,7 \%$ \\
$\begin{array}{l}\text { Lesão nos olhos e nos outros órgãos, podendo } \\
\text { levar à cegueira }\end{array}$ & $12 \%$ & $13,5 \%$ & $15,7 \%$ \\
$\begin{array}{l}\text { Degeneração do cérebro, que ocasiona na perda } \\
\text { da memória recente }\end{array}$ & $10,4 \%$ & $25,2 \%$ & $1,5 \%$ \\
$\begin{array}{l}\text { Degeneração do intestino, que pode causar } \\
\text { câncer neste órgão }\end{array}$ & $11,2 \%$ & $10,9 \%$ & $17,1 \%$ \\
Sem resposta & - & - & $1,6 \%$ \\
\hline
\end{tabular}

Ao serem interrogados sobre as consequências da Toxoplasmose, menos da metade dos alunos das escolas 2 e 3 e um número menor na escola 1 responderam corretamente "lesões nos olhos, podendo levar à problemas de visão ou cegueira, e transmissão dessa doença ao feto em caso de mulheres grávidas" como consequências dessa doença (Tabela 7). Isso indica que os estudantes não possuem conhecimentos básicos sobre esta doença tão negligenciada e perigosa para o homem. 
Tabela 7: Respostas dos discentes para a pergunta 9 do questionário: "A Toxoplasmose é uma doença muito comum em gatos, e por isso sua prevenção consiste em não beijar esses animais e sempre lavar bem as mãos após o contato com os mesmos, pois isso pode trazer algumas consequências. Dentre essas consequências, podemos

\begin{tabular}{lccc} 
citar". & & & \\
\hline Respostas dos estudantes & Escola 1 & Escola 2 & Escola 3 \\
\hline $\begin{array}{l}\text { Lesões nos olhos, podendo levar à problemas de } \\
\text { visão ou cegueira }\end{array}$ & $27,6 \%$ & $46,7 \%$ & $36,9 \%$ \\
$\begin{array}{l}\text { Mulheres grávidas com essa doença podem } \\
\text { transmiti-la ao feto }\end{array}$ & $29,2 \%$ & $22,2 \%$ & $32,7 \%$ \\
$\begin{array}{l}\text { Diminuição ou perda total da função dos órgãos, } \\
\text { como coração e rim }\end{array}$ & $11,8 \%$ & $14,9 \%$ & $16,8 \%$ \\
$\begin{array}{l}\text { Desnutrição e emagrecimento } \\
\text { Sem resposta }\end{array}$ & $31,4 \%$ & $15,6 \%$ & $13,6 \%$ \\
\hline
\end{tabular}

Por fim, quando os alunos foram questionados sobre onde viram as informações tratadas no questionário, e a maioria das respostas foi na Escola, Internet e Televisão. Alguns alunos também disseram já terem visto sobre essas informações na família, farmácia, posto de saúde e em panfletos (Figura 3). Dessa forma, a escola é o ambiente onde os alunos mais veem sobre essas informações, pois é onde passam boa parte do tempo. Valla e Melo (1983) discutem que "a escola pode ser um lugar onde todo mundo discute saúde, pois há muitas oportunidades de se reunir os alunos, os professores, os pais e os moradores".

Assim, é necessário que a educação em saúde seja um tema cuidadosamente abordado por parte das escolas, para que gerem resultados efetivos em relação às doenças fazendo com que os alunos recebam as informações necessárias para buscar melhorias para sua realidade, mas para isso deve-se levar em conta também que esse processo precisa ser acompanhado e incentivado por políticas públicas voltadas à saúde das populações, pois ainda requerem muitos investimentos para que isso aconteça.

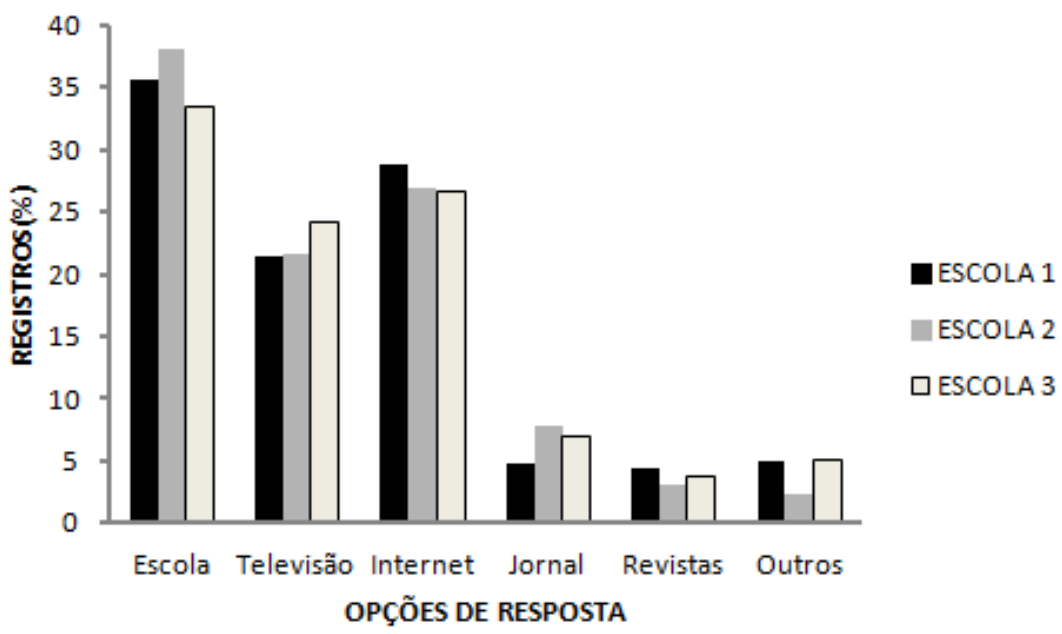

Figura 3: Respostas dos alunos para a questão 10: "Onde você já viu sobre essas informações?” 


\subsection{Análise do questionário dos docentes}

As abordagens do tema em sala de aula, pelos docentes, também foram analisadas. Os docentes das três escolas lecionam para turmas de segundo ano do Ensino Médio e possuem graduação em Ciências Biológicas, a docente da Escola 1 é Mestre, e as docentes das Escolas 2 e 3 possuem Especialização. Todas as docentes disseram ministrar o conteúdo de parasitoses causadas por protozoários em suas aulas, e para isso utilizam recursos como vídeos e slides. Uma das docentes informou que utiliza palestra como recurso para esse conteúdo. Nessa perspectiva, percebe-se a importância que o professor constate as principais dúvidas dos alunos e que a partir disso, planejem mudanças em suas metodologias, principalmente em relação às parasitoses no contexto da saúde (BARBOSA et al., 2009).

Quando questionadas sobre os pontos que devem ter mais enfoque quando se trabalha com o conteúdo de parasitoses humanas, todas as docentes disseram que prevenção e tratamento são os mais importantes, isso demonstra que as docentes consideram que os alunos devem saber as formas de prevenção dessas doenças, principalmente em relação à higiene pessoal, que segundo Belo et al. (2012), são fatores determinantes a prevalência de infecções parasitárias.

Ao serem interrogadas sobre as maneiras que poderiam melhorar o processo de ensinoaprendizagem destes conteúdos, as docentes das três escolas consideram que um maior número de aulas práticas com microscopia é uma forma de auxiliar no ensino deste conteúdo, e somente a docente da escola 2 considera que palestras com profissionais da saúde também contribui para que isso aconteça. Segundo Rangel (1990), a escolha da metodologia a ser utilizada é feita de acordo com o aluno, seu desenvolvimento, conteúdo, sua natureza, com o contexto, ou seja, as características e condições de toda comunidade escolar.

Por fim, foram questionadas sobre o que achavam do livro didático utilizado na disciplina de Biologia, sendo que as docentes da escola 1 e 3 disseram que o livro aborda esse conteúdo de forma bastante condensada, e que muitas vezes é preciso complementar esse conteúdo para abordar em sala de aula, somente a docente da escola 2 disse que o livro aborda esse tema de forma suficiente para a aprendizagem dos alunos.

\subsection{Análise do livro didático}

A análise do livro didático foi realizada a partir de três pontos: conteúdo das parasitoses causadas por protozoários, linguagem utilizada e atividades propostas. O capítulo do livro onde aborda as parasitoses causadas por protozoários trata esse conteúdo de forma bastante superficial, pois são apresentadas em pequenos trechos incluindo a transmissão, agentes causadores, sintomas e algumas formas de prevenção. Doenças como Malária e Doença de Chagas são abordadas de forma mais complexa e detalhada em relação às outras doenças causadas por protozoários, além disso, são as únicas que possuem o ciclo de vida do protozoário esquematizado no capítulo. A linguagem utilizada é um pouco complexa, utilizando expressões bastante formais, além disso, o livro dá bastante enfoque aos nomes científicos dos agentes causadores das doenças podendo dificultar o entendimento do aluno.

Outro ponto analisado foi em relação às imagens dispostas no livro, e nota-se que essas são insuficientes considerando a amplitude desse conteúdo, pois só ilustram dois tipos de vetores (barbeiro e mosquito-palha), e os detalhes de uma casa de pau a pique.

Por fim, foram analisadas as atividades propostas e pode-se perceber que estas são bastante complexas em relação à abordagem desse conteúdo no livro didático, uma vez que inclui várias situações que não tiveram enfoque no capítulo, como: lugares de disseminação da doença, condições que propiciam a transmissão da doença (falta de saneamento básico, clima, temperatura e índices de chuva). 
Dessa maneira, pode- se perceber que o livro didático dispõe o conteúdo das doenças causadas por protozoários de forma insuficiente, uma vez que esse conteúdo deveria ser abordado de forma mais detalhada, pois se trata de doenças comuns na população, além disso, deveria enfatizar pontos como; medidas de prevenção e formas de contágio para que os alunos tomem conhecimento de todas essas informações, segundo os PCN's (BRASIL, 2010), há metodologias como jornais, revistas, computadores, filmes como fontes de pesquisa que podem ser utilizadas para ampliar a abordagem dos conteúdos.

Nesse âmbito é de suma importância que o conteúdo sobre parasitoses seja enfatizado em sala de aula, embora muitas vezes os professores precisem ir além do material pedagógico que recebem para conseguir ministrar esse conteúdo com sucesso, além de outras dificuldades que encontram no cotidiano escolar como falta de tempo hábil para isso, sendo assim essa temática deveria ser uma preocupação não apenas da escola, mas também dos órgãos governamentais, família assim como toda a comunidade escolar e local.

\section{Conclusão}

De acordo com os dados obtidos nessa pesquisa pode-se concluir que o tema parasitoses causadas por protozoários tem sido abordado de forma insuficiente para os discentes, onde alguns pontos ainda poderiam ser trabalhados de melhores maneiras em sala de aula, como: fases clínicas da doença, exemplos de parasitas desse filo e formas de transmissão, pois foi onde houve um número elevado de erros, então isso pode ser aperfeiçoado a partir de estratégias metodológicas como: demonstrações, trabalhos em grupo, pesquisa de campo, recorte e colagens, histórias em quadrinhos que os docentes podem utilizar para concluírem esse conteúdo com sucesso.

Tendo em vista que são doenças bastante disseminadas na população, faz-se necessário que essa temática seja trabalhada tanto no ensino fundamental, quanto no ensino médio, de formas diversificadas, dinâmicas e com atividades avaliativas formativas para acompanhamento da compreensão do aluno, para que os indivíduos tenham uma maior possibilidade de possuir uma qualidade de vida melhor, e as informações necessárias quanto à educação para saúde, pois há condicionantes como: fatores ambientais, falta de saneamento básico, falta de água tratada e condições de higiene que também podem contribuir para a proliferação dessas doenças.

Além disso, os docentes também se mostraram preocupados em passar esse conteúdo dando enfoque a pontos importantes como prevenção e higiene pessoal, além de usarem estratégias alternativas para isso e não se limitarem ao livro didático, apesar de as escolas não disponibilizarem de recursos suficientes como laboratórios e microscópios, para elaborarem aulas práticas a fim de melhorar o ensino-aprendizagem sobre essa temática.

A presente pesquisa propõe que, a educação para saúde e doenças parasitárias são temáticas que requerem maior atenção nas práticas pedagógicas das escolas, de modo a elaborar estratégias para que isso seja trabalhado de forma detalhada, para que formem alunos críticos e conscientes quanto a doenças parasitarias causadas por protozoários, pois, como são doenças que afetam principalmente a população de baixa renda, são muitas vezes negligenciadas.

\section{Referências}

BARBOSA, L.A.; SAMPAIO, A.L.A.; MELO A.L.A.; MACEDO, A.P.N.; MACHADO, M. F.A.S. A educação em saúde como instrumento na prevenção de parasitoses. Revista Brasileira em Promoção da Saúde v. 22, n. 4, p. 272-278, 2009.

BELO, V.S.; OLIVEIRA, R.B.; FERNANDES, P.C.; NASCIMENTO, B.W.L.; FERNANDES, F.V.; CASTRO, C.L.F.; SANTOS, W.B.; SILVA, E.S. Fatores associados à ocorrência de 
parasitoses intestinais em uma população de crianças e adolescentes. Rev Paul Pediatr 2012;30(2):195-201.

BRASIL. MINISTÈRIO DA EDUCAÇÃO. SECRETARIA DE EDUCAÇÃO BÁSICA. Parâmetros nacionais de qualidade para o ensino médio. Ministério da Educação. Secretaria de Educação Básica: Brasília (DF), 2007.

NEVES, D. P. Parasitologia humana, 11 edição. São Paulo, Atheneu, 2005.

OLIVEIRA, H.M.; GONÇALVES, M.J.F. EDUCAÇÃO EM SAÚDE: uma experiência transformadora. Rev Bras Enferm, Brasília (DF) 2004 nov/dez;57(6):761-3.

PAES, N.A.; SILVA, L.A.A. Doenças infecciosas e parasitárias no Brasil: uma década de transição. Rev Panam Salud Publica/Pan Am J Public Health 6(2), 1999.

RANGEL, M. Métodos de Ensino para a aprendizagem e a dinamização das aulas. $2^{\circ}$ edição. Rio de Janeiro, Papirus, 1990.

SILVA, E.M.; ROCHA, M.O.C.; SILVA, R.C.; PAIXÃO, G.C.; BUZZATI, H.; SANTOS, A. N.; NUNES, A.C.P. Estudo clínico-epidemiológico da doença de Chagas no distrito de Serra Azul, Mateus Leme, centro-oeste do Estado de Minas Gerais. Revista da Sociedade Brasileira de Medicina Tropical 43(2):178-181, mar-abr, 2010.

SILVA, C.G.; SANTOS,H.A. Ocorrência de parasitoses intestinais da área de abrangência do centro de saúde Idelfonso da região Oeste da Prefeitura Municipal de Belo Horizonte, Minas Gerais (Brasil). Rev. Biol. Ciênc. Terra, v.1, n.1, 2001.

VALLA, V.V.; MELO, K.A.C.; Sem educação ou sem dinheiro? A saúde em estado de choque. Rio de Janeiro, Espaço e Tempo; Janeiro, 1983.

WORLD HEALTH ORGANIZATION. Neglected tropical diseases, hidden successes, emerging opportunities[Internet]. 2006.2 Disponível em <http://whqlibdoc.who.int/hq/2006/WHO_CDS_NTD_2006.2_eng.pdf> . Acesso em 10 de Outubro de 2017. 